\title{
Los años juveniles de Juan Carlos Portantiero (1952-1963)
}

\section{The young years of Juan Carlos Portantiero (1952-1963)}

DOI: https://doi.org// 0.32870/eees.v26i76.7094

José María Casco*

\section{Resumen}

El presente artículo analiza los años de formación del pensador argentino Juan Carlos Portantiero como intelectual publico. El objetivo es reconstruir su trayectoria para mostrar cómo la figura del intelectual está indisolublemente ligada a redes, espacios de socialización y a un ejercicio de la práctica de escritura, lo que pone en cuestionamiento la idea de que los intelectuales son genios naturales. Se reconstruyen sus años de militancia en el Partido Comunista argentino y sus polémicas, se identifica a sus maestros y pares generacionales $y$, por ultimo, se analizan las causas de su salida del partido.

Palabras clave: Juan Carlos Portanteiro, intelectualidad, redes, comunismo argentino, años de formación.

\begin{abstract}
This article analises the formation years of the Argentinian thinker Juan Carlos Portantiero as a public intellectual. The aim is to reconstruct his career path to show how the intellectual figure is indissolubly linked to networks, spaces for socialization and to an exercise in the practice of writing, which puts into question the idea that intellectuals are natural geniuses. His years of militancy in the Argentinian Partido Comunista (Communist Party) and its controversies are reconstructed, his teachers and generational peers are identified and, finally, the causes of his departure from the party are analyzed.
\end{abstract}

Keywords: Juan Carlos Portanteiro, intellectuality, networks, Argentinian communism, formation years.

\footnotetext{
- Profesor-Investigador de la Facultad de Ciencias Sociales de la Universidad de Buenos Aires (UBA) y de la Universidad Nacional de San Martín, Argentina. ORCID: https://orcid.org/00000002-8375-6617_casco.josemaria@yahoo.com.ar

Fecha de recepción: 17 de febrero de 2019. Fecha de aceptación: 28 de mayo de 2019.
} 


\section{Introducción}

Para poder desarrollar su vocación de intervenir en la vida pública, los intelectuales necesitan un ambiente donde midan sus ideas y también las cultiven, a través del contacto ya sea con un maestro, con su grupo de pares o con ambos. De ahí que los que se inicien en la actividad intelectual deban integrarse a espacios institucionales organizados para el cultivo de la cultura y de las ideas.

Este artículo busca revisar el proceso de inicio formativo del intelectual argentino Juan Carlos Portantiero, en particular sus años al interior del Partido Comunista (PC) de su país. Para ello, el texto revisa, primero, su itinerario intelectual; luego, se concentra en los espacios de sociabilidad que le dieron forma y las instituciones que lo cobijaron; y finalmente se enfoca en sus maestros y los temas que moldearon su formación.

\section{El comienzo de un largo camino. El partido como escuela para la formación intelectual}

1963 fue un año que sirvió como parteaguas en la joven carrera de Juan Carlos Portantiero como militante político: fue el año de su expulsión del Partido Comunista (PC) argentino, al que había ingresado en 1952 de forma accidental, luego de intentar afiliarse al Partido Socialista. ${ }^{1}$ Portantiero llegó a la sede del PC de la calle San Pedrito, en el barrio de Flores (Buenos Aires). Se incorporó primero al frente

I.En varias oportunidades, Portantiero atribuyó a un error su ingreso al PC a través de una anécdota. En ella, contaba que junto a un grupo de amigos de su barrio había tomado la decisión de ir a la Casa del Pueblo, sede central del Partido Socialista, a afiliarse, y como el grupo no había sido recibido de buena manera, y luego de un interrogatorio que los intimidó, decidieron irse y no volver. Dicho episodio hizo que, ante la insistencia de Néstor Spangaro, un militante comunista del barrio, se afiliara, finalmente, al comunismo, esto en la sede del partido en cuestión en el barrio de Flores (Tortti y Chama, 2006; Mocca, 20I2).

\section{0}


universitario y pasó rápidamente a militar en la Casa de la Cultura² (ubicada en Córdoba y Riobamba, en la misma capital argentina), esto debido a sus veleidades literarias y culturales (Mocca, 2012). Ese mismo año, comenzó a estudiar derecho en la Universidad de Buenos Aires (UBA), impulsado por su familia, que buscaba para el joven un futuro próspero en el bufete jurídico de un familiar. Portantiero abandonaría ese mundo formal para pasar a la carrera de Letras en la Facultad de Filosofía de la misma universidad. Tras cursar todas las materias introductorias, interrumpió sus estudios para dedicarse sólo a la militancia política.

Fue allí donde entabló un vínculo decisivo con Héctor Pablo Agosti, el intelectual más importante del Pc por esos años y quién acompañó el desarrollo de su vocación política e intelectual. En 1955, empezó a desempeñarse como periodista en el semanario Nuestra palabra, cuando ya había trabajado por dos años en algunas de las editoriales del partido. En ese contexto, también trabó relación con Rodolfo Ghiodi, uno de los dirigentes más encumbrados y director de la publicación -a Agosti lo conocería después, cuando este asumiría la dirección del semanario en 1958-.

En la redacción, hizo lazos de camaradería y amistad con jóvenes promesas como Juan Gelman, Roberto "Tito" Cossa y Andrés Rivera. A todos ellos los unió, además de un impulso generacional y una visión del mundo conjunta, la pasión por la literatura y el cine neorrealista italianos de la posguerra. Pavese, Pratolini y De Sica eran algunos de los nombres que aparecían entre los jóvenes como modelo e inspiración para el análisis literario, pero también político y social. De ahí que sea posible decir que la cultura italiana marcó el modo en que esos jóvenes se colocaron con voz

2. La Casa de la Cultura Argentina fue una iniciativa que la dirigencia del PC llevó adelante en 1952 como parte de una propuesta que pretendía unificar todas las acciones del Frente Cultural del partido que hasta ese momento, según sus dirigentes y también algunos intelectuales, se encontraban fragmentadas (Massholder, 20I3; Petra, 20I7).

Teoría y Debate 8 No.76 
propia dentro del PC. ${ }^{3}$ En efecto, de la mano de Agosti, el más liberal y culto de los escritores comunistas, los noveles periodistas y críticos literarios se apartaron de las lecturas del partido en materia política, pero también estética. Así, cuestionaron la teoría del realismo socialista consagrada por Zdhanov, que había sido adoptada como el verdadero arte socialista y como guía privilegiada en materia artística para el Frente Cultural.

En este sentido, Agosti buscó una apertura a otros lenguajes, dentro de los que se destacaron autores franceses e italianos que tuvieron un papel protagónico para el Frente Cultural. Revistas como Il Contemporáneo, Rinascita, Societá y Crítica marxista (a la que Portantiero estaba suscrito vía una librería italiana del barrio de San Telmo) fueron las fuentes para construir un proyecto de renovación de la cultura comunista. De algún modo, esa marca generacional que los jóvenes militantes, y Portantiero como parte de ese grupo, desplegaron hasta 1963 fue la que los dejó fuera del partido.

2. Agosti, Gramsci y la formación de una cultura política ilustrada

Hacia 1959, el Gobierno de Arturo Frondizi clausuró algunos órganos de difusión del Pc, entre ellos Nuestra palabra. Así fue como Portantiero y Agosti se integraron a Cuadernos de cultura, la revista oficial y más importante de los comunistas, el primero como secretario de redacción y el segundo como director. Forjaron un vínculo no sólo laboral, sino de discípulo-maestro, por medio del cual Portantiero descubrió la obra de Antonio Gramsci.

El primer contacto de Portantiero con la obra del italiano, de un modo un tanto superficial según sus palabras (Por-

3. Para una reconstrucción exhaustiva del influjo que tuvo esa cultura italiana sobre esos jóvenes intelectuales, véase: Petra (2017).

\section{2}


tantiero, 2005), lo había tenido cuando entre los años 1953 y 1955 ingresó como empleado a Lautaro, una de las tantas iniciativas editoriales con las que el PC contaba. ${ }^{4}$ Fue desde ese sello que Agosti impulsó la traducción de Los escritos de la cárcel, disponible al momento. También gracias a esa iniciativa, Portantiero conoció a José María Aricó cuando este tradujo las Notas sobre Maquiavelo, sobre la política y el Estado moderno, en 1962. Como hicieran tantos escritores en una tendencia que se remontaba hacia los comienzos del campo literario en los años veinte, maestro y discípulo compartieron el oficio de periodista en el diario Clarín.

En dicho matutino, Portantiero trabajó entre 1959 y 1965 de forma rotativa por diferentes secciones, hasta que en 1962 se convirtió en columnista de la sección de espectáculos bajo el seudónimo de Martín Millán. ${ }^{5}$ Así, desde mediados de la década del cincuenta hasta mediados de la siguiente, las redacciones de diarios y revistas fueron el ámbito de formación de su oficio de escritor y crítico cultural, y el escenario privilegiado para el desarrollo de su vocación intelectual, imbricado fuertemente con la historia y la política del momento. Allí, adquirió la destreza para la síntesis y la condensación de ideas en unas pocas páginas que fue la marca de sus intervenciones en muchos de sus posteriores escritos. Fue en esos escenarios, y en la gran escuela que el partido supo ser, donde su habitus de escritor cobró forma.

Si bien dentro del Pc había una separación entre el ala política y el ala cultural expresada en la división del trabajo,

4. Massholder (20I3) sostiene que a fines de los años cincuenta los sellos editoriales comunistas eran Cártago, Lautaro, Fundamentos, Platina, Proteo, Procyón, Problemas, Capricornio, Anteo, Futuro, Partenón, Argumentos y Arandu. 5. En una entrevista personal, realizada en octubre de 2006, el intelectual había manifestado que su seudónimo obedecía a que en el diario sólo trabajaba para obtener un salario que pudiera completar sus ingresos, y que dado que era una persona conocida dentro del partido hacia 196 I el uso de seudónimo lo ayudaba a desligar su trabajo en el diario de su militancia partidista (Portantiero, 2006). El presente artículo no se ocupa de su rol como periodista en el diario Clarín por considerar que allí no desarrolló su papel de intelectual comprometido con la política. 
la política era el nervio que mantenía activa la labor partidaria y se constituía en su eje central. Es en ese sentido que Portantiero se convirtió en un intelectual dreyfusard: una figura con un tipo de intervención donde el oficio y el prestigio ganado como escritor eran puestos al servicio de causas más generales que remitían a valores trascendentales (Coser, 1968).

En estos años de formación, el comunismo fue su causa, aunque luego se colocó como defensor del ideario socialista en varias de sus versiones. Esa fue una de las razones por las cuales Gramsci gravitó profundamente en sus reflexiones. Este, como se recordará, además de militante del partido, era un intelectual con una concepción política donde la dimensión cultural era central y en el marco de la cual los intelectuales eran considerados actores privilegiados.

En su ideario, la cultura nacional que portaban los sectores subalternos debía fusionarse con la de los intelectuales para formar un solo bloque histórico, y esa era la tarea primordial que el comunismo debía llevar a cabo. Ese papel que se les asignaba al intelectual y al partido marcó a Portantiero y a muchos otros de su generación que, como él, buscaban ser protagonistas en la escena nacional. En ese sentido, los libros de Gramsci (Los intelectuales y la organización de la cultura, Literatura y vida nacional y Maquiavelo o el nuevo príncipe moderno) funcionaron como un prisma para enfocar una estrategia política diferente del modelo soviético y contribuyeron a su inspiración como escritor, todo esto bajo la tutela de Agosti.

\section{Hacia la revolución}

Entrados los años sesenta, la coyuntura local e internacional cumplió un rol decisivo en la producción de cruces y desplazamientos en el mundo político y cultural. En estas circunstancias, muchos intelectuales decidieron pasar a la

\section{4}


arena de la acción, como es el caso de Portantiero después de 1963. Tres acontecimientos dejarían su marca en el mundo de la izquierda, producirían un proceso de reacomodo en sus filas y cuestionarían las posiciones hegemónicas de los partidos tradicionales en ese espacio ideológico:

1. La persistencia del peronismo como lugar de la identidad obrera y de los sectores populares luego de su caída en 1955, y los intentos fallidos por borrar al movimiento del mapa político; ${ }^{6}$

2. El informe Jruschov de 1956 sobre los crímenes de la era stalinista en la Rusia soviética, que produjo un cisma en el mundo comunista; y

3. La Revolución cubana y su impacto en los sectores juveniles. ${ }^{7}$

En efecto, el triunfo de la Revolución cubana y la adhesión al marxismo a partir de 1961 de la cúpula dirigente del PC de ese país se convirtieron en el centro de gravedad sobre el que giró todo el mundo político e intelectual de la izquierda latinoamericana por esos años. Como tal, los hechos desplazaron a los partidos tradicionales como lugar de identidad para los jóvenes de la izquierda y colocaron las coordenadas para el pensamiento y la acción de sus militantes.

En esa dirección es que debe entenderse la irrupción de nuevas revistas y fracciones dentro del PC y el Partido Socialista. ${ }^{8}$ También, es por esa vía que se entabló la disputa entre viejos y nuevos dentro del Pc. De hecho, el partido no admitía disidencias a las líneas estratégicas que había tra-

6. Para una reconstrucción detallada de la persistencia de la identidad peronista en los obreros, véase: James (2010).

7. Es extensa la bibliografía sobre el impacto del informe Jruschov, lo mismo que sobre la Revolución cubana. En ese sentido, a modo de ejemplo, se remite a Sigal (2002), Altamirano (20I2), Gilman (2003), Sarlo (200I), Terán (1993), Tortti (2009) y Burgos(2004).

8. Para una buena reconstrucción sobre este proceso, véanse los trabajos de Tortti (2009 y 2013).

Teoría y Debate No.76 
zado, pero pronto los jóvenes alentados por Agosti emprendieron la tarea de ensanchar al marxismo que los cobijaba.

También en ese marco es que Agosti llevó a cabo la tarea de incluir a Gramsci como repertorio de sus reflexiones. Sus libros Echeverría (de 1951) y Nación y cultura (de 1959) estuvieron sostenidos por categorías gramscianas que buscaban establecer un lugar de filiación de su posición en una tradición democrática nacional-popular. Al colocarse por fuera de posiciones de tipo revisionistas y liberales, Agosti remontaba la marca de origen que debía seguir el partido a los tiempos de Echeverría y la generación del $37 .{ }^{9}$

Esa huella y el tono que le imprimía Agosti a sus análisis fueron una estela que recorrió el primer libro de Portantiero, Realismo y realidad en la narrativa Argentina, editado en 1961. Así, discípulo y maestro cumplieron con la tarea de buscar otras matrices a las establecidas para renovar al partido y colocar otro marxismo para que este encontrara las coordenadas de una estrategia que lo volviera a conectar con las masas, y fuera también retórica y politicamente la verdadera expresión de la clase obrera.

\section{Ser o no ser. ¿Qué hacer con Perón y el peronismo?}

En efecto, la caída del Gobierno de Perón no redundó en un acercamiento de las masas al PC que, como creían muchos de sus dirigentes, las representaba de modo natural. Si la cultura italiana fue el factor mediante el cual los jóvenes colocaron su disputa en términos intelectuales para alejarse del canon estalinista, en el terreno político el peronismo primero y la Revolución cubana después fueron los acontecimientos que pusieron en cuestión tanto las lecturas como las estrategias que debía seguir el partido.

9. Para un análisis de la obra de Agosti, véanse: Massholder (20 I 3) y Aricó (I 988).

\section{6}


El PC contaba con un Frente Cultural en el que artistas y escritores encontraban un lugar para desarrollar su vocación intelectual, ya que el partido los proveía de un escenario amplio para las discusiones culturales. Sus revistas y la inauguración, a partir de 1952, de la Casa de la Cultura Argentina eran los ámbitos donde ese frente debatía las condiciones para la creación del hombre nuevo.

Agosti encontró allí un ámbito propicio para desarrollar sus iniciativas, que buscaban colocar un punto de vista comunista que se diferenciaba del ala liberal del campo cultural y también del ala nacionalista que, por ese entonces, comenzaba a hegemonizar el peronismo. ${ }^{10}$ Como sucedía con todo buen comunista, el realismo socialista era la doctrina con la cual Agosti debía interpretar la realidad, al igual que lo hacían otros intelectuales y artistas, pero el que alentaba Agosti como movimiento estético distaba mucho de las coordenadas que había trazado Moscú vía las codificaciones con las que Zdhanov había escrito la teoría oficial del socialismo en 1939.

La codificación soviética se sustentaba en tres puntos fundamentales (Crespo, 1999, p. 425):

1. Impedir todo contacto con el extranjero, y especialmente con occidente;

2. Vetar toda expresión artística que se apartara del canon del realismo socialista por ser este el único modo de producción de obras de accesibilidad a la sensibilidad y conocimiento del hombre común, alejado de cualquier tinte que pudiera ser considerado modernista en todas sus expresiones, ya fueran estas las del formalismo, el decadentismo o la abstracción;

3. Garantizar que todas las formas de expresión artísticas fueran promotoras activas y explícitas del optimismo de la Unión Soviética.

10. Para una reconstrucción de la izquierda nacional de impronta peronista, véase: Ribadero (2017). 
Agosti combatía por darle otro contenido al realismo. En su concepción, las expresiones estéticas debían atender a la realidad nacional, por lo que las directivas de los rusos no podían ser una guía, pues estaban supeditadas a la teoría del reflejo y las leyes de la historia según el manual que establecía el marxismo-leninismo de factura stalinista.

De ahí que fueran otras las fuentes en las que Agosti abrevara para construir su mirada realista: la traducción de las obras de Gramsci, junto a obras de autores franceses y a su combate, desde la dirección de Cuadernos de cultura, contra el dogmatismo de muchos escritores que se supeditaban al canon soviético. ${ }^{11}$

Con todo, ese impulso renovador no iba a estar exento de problemas. El ala cultural gozaba de una autonomía relativa dentro del partido, por la que las discusiones literarias y estéticas podían llevarse adelante siempre y cuando esto no implicara el corrimiento de las líneas políticas que la dirigencia partidaria adoptaba. Así, cuando en 1956 se llevó a cabo la primera reunión de intelectuales comunistas, Agosti se vio fuertemente cuestionado por una de las autoridades máximas del PC.

En esos momentos, algunos intelectuales de las revistas Propósitos y Cuadernos de cultura mantenían una disputa entre los defensores del realismo de Zdhanov y aquellos que, como Agosti, pugnaban por combatir el sectarismo, pero en dicha ocasión Rodolfo Ghioldi, el único dirigente político que tenia credenciales suficientes para intervenir con autoridad en el espacio cultural, sentenció: "Yo le beso los pies al último de los escritores soviéticos" (Massholder, 2013, p. 92), lo que cerró el debate y dejó en claro qué línea no se podía cruzar.

El episodio, no menor, ilustra bien dos problemas. Por un lado, la subordinación que el ala cultural tenía respecto

I I.Para un análisis pormenorizado de las disputas estéticas que daría Agosti en sus libros y los órganos intelectuales partidarios, ver: Massholder (2013) y Petra (2017).

\section{8}


de la dirigencia política, incluso cuando esto no impedía que algunas iniciativas pudieran llevarse adelante, como lo muestran las publicaciones de Gramsci. Por otro lado, el clásico problema de la tensión entre los hombres de ideas y los hombres de acción.

Mannheim (1963) ha mostrado algunas de las particularidades que adquirió esa tensión en sus análisis sobre las condiciones que hacen al intelectual y su posición psicológica en el mundo social. Así, sobre la característica del intelectual que define como intersticial, esto es, entre pero no sobre las clases, anota:

su educación le ha preparado [al intelectual] para enfrentarse con los problemas cotidianos desde varias perspectivas y no sólo desde una, como hacen la mayoría de los que participan en las controversias de su tiempo.Su preparación adquirida le hace, potencialmente, más inestable que otros individuos [...], es capaz de experimentar, a la vez, varias aproximaciones en conflicto a la misma cosa [...]. No podemos explicarnos esas cosas si aceptamos las simplificaciones propias del funcionario del partido o de una sociología de clase. (Mannheim, 1963, pp. I55- I56)

Lo transcrito es adecuado para referir a los motivos por los cuales se produce una tensión entre los hombres encargados de la creación y los hombres de acción, mucho más proclives, en este caso, a la disciplina partidaria. Era precisamente dentro del partido y desde esta lógica donde se producía este choque. Quizás aquí, como en ningún otro lado, se juegue el drama del intelectual, ya que la razón de partido es opuesta a la razón universal -o de cualquier otro orden- que aquel siempre reclama. Los años aquí comentados ejemplifican bien los problemas no sólo generacionales en el seno del comunismo, como bien ha sido señalado, sino también los que acarrean dos papeles sociales que tienden a enfrentarse en tanto uno no se subordine al otro. 
En efecto, en el partido esas tensiones no sólo no iban a desaparecer, sino que iban a ir in crescendo hasta alcanzar su clímax a mediados de los años sesenta. Agosti no se reveló frente a las contundentes declaraciones del buró político y sus directivas. Eso ocupó a Portantiero y a un grupo de jóvenes cuando, ya entrados en dicha década, revalorización del peronismo mediante y bajo el acicate que significó la Revolución cubana para el mundo de las izquierdas, pugnaron por darle otra orientación teórica a la estrategia de clase del partido.

En ese sentido, las disidencias entre maestro y discípulo aparecieron cuando los jóvenes jugaron su lugar en el espacio partidario de modo contundente. Agosti, en cambio, alentaba los aires de renovación, pero retrocedía en sus posiciones cuando la dirigencia política los juzgaba por herejes. Una nota da cuenta justamente de ese episodio: cuando en 1963 se llevó a cabo el juicio a Portantiero, acusado de impulsar iniciativas vistas como heréticas, en la sede que el partido tenía en el barrio de Paternal, Agosti le dijo a sus allegados: "Le estuve tirando sogas toda la noche para salvarse, y no agarró ninguna"12 (Mocca, 2012, p. 68).

\section{Ortodoxos y renovadores o viejos \\ y nuevos en busca del marxismo}

En cuanto a la expulsión de Portantiero del partido, ya se ha dicho dicho cuáles fueron algunos de los factores que promovieron la rebelión de sus militantes más jóvenes. Ahora toca hacer referencia a uno de sus vehículos privilegiados, la revista Pasado y presente. La publicación, en efecto, provocaría un enconado problema dentro de las filas del

12. No era la primera vez que un militante era excomulgado de las filas del PC: en 1948, un dirigente muy importante en la jerarquía partidaria, Juan José Real, había sido expulsado a través de un jury por su acercamiento a las políticas del peronismo (Massholder, 20I3). 
partido. La iniciativa editorial estuvo a cargo de un grupo cordobés formado por sectores juveniles que militaban unos en la universidad y otros en la dirección partidaria. Aricó, Schmucler y Del Barco serán los apellidos de algunos de sus animadores principales y quienes disputarán, desde las páginas, las líneas del PC. ${ }^{13}$

En el número uno, que vio la luz en junio de 1963, Portantiero publicó un artículo que colocó la disidencia en un punto de no retorno. El PC tenía un diagnóstico acerca de los problemas de Argentina, que sostenía que la revolución burguesa había sido inconclusa. De acuerdo con esto, lo que el partido debía propiciar era un frente democrático con los sectores progresistas de la burguesía, como primer paso para una revolución social de acuerdo con los preceptos stalinistas.

Para Portantiero, en cambio, la burguesía no podía cumplir un papel importante desde una perspectiva de izquierda, aliada como estaba al capital imperialista con el que no hacía más que perpetuar el carácter dependiente del país. De ahí que la revolución debía ser social, y el proletariado debía cumplir un doble papel: por un lado, arrancar del atraso al país, y por otro, hacer la revolución socialista en un mismo movimiento.

Siguiendo a Cooke y a Guevara, Portantiero sostenía que revolución nacional y revolución social formaban parte de un mismo proceso, lo que cuestionaba las directrices del partido y volvía obsoleto su diagnóstico, al tiempo que colocaba del lado de las filas enemigas a los sectores con los que el PC hacía una alianza.

En su primer artículo, titulado "Política y clases sociales en la Argentina actual", abría el análisis con el siguiente interrogante: ¿vive la sociedad argentina una crisis de la

13. Si bien la iniciativa fue del grupo cordobés, Portantiero estuvo en la génesis de la empresa a través de un intercambio de cartas con Aricó. Allí, según contó el propio Portantiero en varias oportunidades, los dos sugirieron el nombre de Pasado y presente para la publicación. 
política? El nervio de toda la indagación, como su título lo indica, era un análisis de la coyuntura y su crisis. De acuerdo con esa afirmación, esta era el producto del desajuste entre el crecimiento de fuerzas sociales nuevas en la segunda etapa del crecimiento industrial -que arrancó en los años treintay las instituciones políticas creadas en una etapa anterior, que no podían ya contener a las nuevas clases.

En ese sentido, Portantiero delataba al peronismo como la expresión más notoria de esa crisis. El hecho podía ser disimulado en el ciclo de expansión económica, pero ahora la sociedad yacía en un momento crítico y las salidas de tipo reformista mostraban su inviabilidad, mientras la agudización de la lucha de clases operaba como otro hecho que la condicionaba. Porque esos momentos de crisis, diría Portantiero, eran en los que las intermediaciones políticas dejaban de ser los intérpretes ilusorios de la sociedad global y mostraban la decadencia de los partidos políticos.

Portantiero sostenía que la burguesía nacida con los años treinta no pudo implantar sus élites en el seno de la sociedad política. Eso se combinó con una crisis profunda de la estructura económica "que ha agudizado la lucha entre los asalariados y los dueños de los medios de producción, creando una típica situación revolucionaria" (Portantiero, 1963, p. 18), la que, de acuerdo con Lenin, se produce cuando los de arriba ya no pueden mantener su dominación y los de abajo ya no soportan las condiciones de explotación en el mismo grado que en los tiempos de paz, lo que los lleva a una movilización con un alto grado de acción en sentido independiente. Así, en el marco de una crisis que se vislumbraba como estructural, Portantiero acometía un análisis leninista de las clases, caracterizaba las contradicciones que los desajustes ponían en la superficie del sistema y apuntaba que la clase obrera aún mantenía un punto de vista económico corporativo en su conciencia de clase, pero 
que este era el primer índice para "justipreciar la situación revolucionaria que vivimos" (Portantiero, 1963, p. 19).

No debemos olvidar que este estado de las cosas aparecía en momentos en que Portantiero todavía se encontraba en las filas del partido aunque no amparado, al menos aparentemente, bajo su tutela. Es cierto que la línea de interpretación leninista mostraba su marca en el intelectual, pero cuando este caracterizaba la crisis no aparecían juicios moderados ni visos de proponer una salida reformista. Esto significaba colocar un juicio disidente de la estrategia partidaria. ${ }^{14}$

En el mismo año de 1963, en el décimo segundo congreso del PC, Victorio Codovilla, su máximo dirigente, había sostenido que "en el país[,] si bien estaba madurando una situación revolucionaria, no existen aún las condiciones subjetivas para el triunfo socialista" (Massholder, 2013, p. 245). Ese juicio no se diferencia en nada del de Portantiero, pero no debe olvidarse que los acontecimientos de la Revolución cubana colocaron al partido en una situación incómoda, donde, por un lado, se saludaba la gesta del pueblo y se organizaban campañas de solidaridad, pero, por otro, los métodos insurreccionales eran condenados como no adecuados para la instauración de la revolución.

De la misma forma, ya antes, en 1952, el partido había llamado a apoyar lo bueno y criticar lo que está mal del peronismo, aunque en los sesenta esa posición ambigua le traería malestar entre sus filas, sobre todo en los sectores juveniles que saludaban la gesta de "El Che" Guevara con acalorado entusiasmo. La dirigencia, por su parte, no dejaba de apuntar que el camino era cumplir las etapas previstas

I4. Debe recordarse que la coyuntura de 1963 estaba caracterizada por una profunda crisis política luego del derrocamiento del Gobierno de Arturo Frondizi. Dos fracciones de las fuerzas armadas se enfrentaban en las calles, los denominados azules y los colorados, que buscaban unificar posiciones para conducir el rumbo de los acontecimientos políticos del país. En esa disputa dramática, el PC decidió apoyar al bando de los azules, para lo cual movilizó a sus militantes, principalmente a las fracciones juveniles (Altamirano, 2012, p. 194). 
para los países que no habían asistido a las revoluciones burguesas, de acuerdo con la codificación que establecía el estalinismo. El materialismo dialéctico y las leyes de la historia que este contenía eran, para los dirigentes del PC, el camino correcto por el que se debía transitar.

Portantiero avanzaba, por el contrario, en el análisis al describir cómo los sectores burgueses y la vieja oligarquía ligada a la ganadería encontraban soluciones de corto plazo que no remediaban la crisis hegemónica. Bajo ese examen, Perón había impulsado una salida "bonapartista mediante la cual logró detentar el poder en aparente alianza con la clase trabajadora y en real alianza con las viejas clases dominantes [...] que pudo sostenerse gracias a la favorable coyuntura económica" (Portantiero, 1963, p. 20).

Sin embargo, fracasado el proyecto integracionista de Frondizi, y en el marco de una agudización de la lucha de clases donde las bases obreras rebasaban la contención que sus burocracias sindicales les intentaban imponer, Portantiero sentenció que

El esqueleto de la Argentina ha quedado al descubierto: definitivamente no quedan salidas burguesas para la situación nacional [...]. El crecimiento de las fuerzas productivas entró ya en violenta contradicción con el conjunto del sistema y el país ha pasado a vivir un momento histórico en el que la necesidad de la revolución ha llegado a la madurez desde el punto de vista económico y social [...], todos los datos objetivos, de carácter económico-social, indican que en la sociedad argentina ha concluido su ciclo útil el sistema capitalista [frente a lo cual] sólo quedan el proletariado y los demás sectores asalariados como alternativas reales para crear el nuevo bloque histórico con función hegemónica sobre la sociedad nacional. (1963, pp. 22,23)

Desde esa opinión, el partido de Portantiero no jugaba ya ningún papel para una estrategia de izquierda. En esa dirección, se preguntaba si estaba diseñada, por la acción 
de las masas, la nueva sociedad que debía ser reemplazo, y se respondía que "la autoconciencia histórica de una clase no es un proceso espontáneo, ni siquiera crítico teórico. Es un proceso teórico práctico, sólo vigente a través de la experiencia concreta, de la praxis social" (Portantiero, 1963, p. 22), aunque no le asignaba ninguna tarea al partido al cual pertenecía (este no era nombrado ni una sola vez).

Contrariamente a lo supuesto, Portantiero no designaba al PC como el depositario de la vanguardia posibilitadora de la conciencia socialista que, en vísperas de la situación, las masas necesitaban para remplazar a la sociedad capitalista. También por esto, no tardaría muchos meses en llegar el jury que el partido le impondría para dejar definitivamente atrás su capítulo comunista.

\section{Como un jardín de senderos que \\ se bifurcan. La avanzada juvenil}

El partido le había facilitado a Portantiero un universo de trazos ideológicos trascendentes con el cual identificarse. Principalmente, le había permitido aprender un oficio (el de periodista) y colaborar en algunas de sus más importantes revistas. Allí, pudo darle cauce a su naciente vocación, en los ámbitos ideales para la formación cultural que son esas microsociedades que las redacciones conforman. Como señaló Coser, estos son lugares naturales para el desarrollo intelectual porque "todos los intelectuales necesitan un contacto permanente con sus iguales y un público al cual dirigirse" (Coser, 1968, p. 35). Las redacciones de las revistas le habían otorgado a Portantiero justamente eso: una camaradería que funcionó como la plataforma para construir una posición y al mismo tiempo un espíritu de grupo. En ese medio cultural partidario y en sus redacciones, se formó la generación que, apenas comenzados los 
años sesenta, cuestionaría fuertemente las orientaciones comunistas.

Como se ha señalado antes, Juan Gelman, Roberto "Tito" Cossa y Andrés Rivera, además de ser sus camaradas, entablaron con Portantiero relaciones de amistad y fueron todos jóvenes disidentes del ala cultural. En efecto, el grupo de poesía Pan Duro, que orientaban Juan Gelman, Carlos Alberto Brocato y José Luis Mangieri, comenzó por esos años a manifestar su descontento con las orientaciones partidarias. Eso quedó claro en 1964, cuando los referidos impulsaron la edición de la revista La rosa blindada y el partido, a través del comité cultural, la censuró.

Brocato expresó entonces de modo elocuente su disconformidad en un intercambio epistolar con un dirigente partidario. Allí, sostenía que "el PC argentino no demostraba su influencia en las masas ni su papel de vanguardia[,] y que era sólo una buena y poderosa máquina administrativa [...] una dirección petrificada [donde] toda crítica choca contra un muro" (Massholder, 2013, p. 290).

En la misma dirección se pronunciaron los artistas plásticos en una reunión partidaria que tuvo lugar en enero de 1963. Allí, el pintor Helio Casal señalaba que los problemas son el resultado de

una crisis de fe que empieza en el $x x$ Congreso [del partido] [...] porque no se han discutido a fondo los coletazos del culto a la personalidad en nuestro propio partido ni sus remanentes, que se manifiestan en cuestiones de método, en persistencia de camaradas que nunca se equivocan, en una rigidez dógmatica que no permite desarrollo, creadores, etc. (Massholder, 20I 3, p. 290)

En la misma reunión, el pintor Norberto Onofrio alertaba sobre "una crisis de confianza en el partido", y Carlos Gorriarena sentenciaba que el mismo carecía de respuesta mientras iba "de derrota en derrota" (Massholder, 2013, pp. 
291-293). Fue en ese clima de ruptura que muchos intelectuales comenzaron a tomar la decisión de crear vínculos más allá de las direcciones partidarias.

También en ese mismo sentido hay que entender la intervención de Portantiero en el primer número de Pasado y presente, que además contenía un editorial escrito en un tono poco proclive a la disciplina partidaria. En efecto, en una larga comunicación, Aricó (1963) sentenciaba allí que la generación que daba vida a la publicación era

una generación que no reconoce maestros, no por impulsos de simplista negatividad, sino por el hecho real de que en nuestro país las clases dominantes han perdido hace tiempo la capacidad de atraer culturalmente a sus jóvenes, mientras, el proletariado y su conciencia organizada no logran aún conquistar una hegemonía que se traduzca en una coherente dirección intelectual y moral. (p. 2)

Esto desligaba a la publicación de toda filiación con el partido. De ahí que el joven dirigente cordobés afirmara que la publicación

será por ello la expresión de un grupo de intelectuales con ciertos rasgos y perfiles propios, que esforzándose por aplicar el materialismo histórico e incorporando las motivaciones del presente, intentará soldarse con un pasado al que no repudia en su totalidad pero al que tampoco acepta en la forma en que se le ofrece. (Aricó, 1963, p. 3)

Había llegado la hora de las renovaciones, y por eso Aricó terminaba arremetiendo que

es preciso en primer lugar reconocer la validez de la instancia generacional, no tener nunca miedo de la obsesión por ver claro, de la "irrespetuosidad" del lenguaje, del deseo permanente de revisión del pasado que la caracteriza.Y además, comprender cómo se desarrolla 
y cambia la realidad, no permanecer nunca atados a viejos esquemas, a viejos lenguajes y posiciones. (1963, p. 7)

Viejo y nuevo, formas prototípicas de la lucha generacional aparecían en forma explícita y, así, mandaban al desván del recuerdo las líneas que la dirigencia del partido trazaba como estrategia política e intelectual.

Frente a la embestida de los cordobeses, la respuesta del partido no se hizo esperar. El número 66 de Cuadernos de cultura estuvo dedicado a responder los ataques de Pasado $y$ presente, aunque hay que subrayar que el inicio de las tensiones con el grupo se había suscitado un tiempo antes, cuando en el número 58 de Cuadernos de cultura (julio-agosto de 1962) Raúl Olivieri, miembro de la comisión de estudios filosóficos del partido, publicó un artículo titulado "El problema del determinismo en el materialismo dialéctico".

El texto de Olivieri fue contestado por Oscar del Barco en el número siguiente de la misma revista, con su escrito "Notas sobre Antonio Gramsci y el problema de la objetividad". La discusión giraba alrededor del problema de la objetividad y el conocimiento. En la argumentación de Olivieri, bajo la guía teórica del Lenin de Materialismo y empiriocriticismo, la realidad podía establecer relaciones objetivas independientemente de cualquier sujeto cognoscente, puesto que estas "constituyen pautas inmanentes del ser y del devenir" (Olivieri, 1962, citado en Burgos, 2004, p. 54).

Del Barco, por el contrario, sostenía un argumento de factura kantiana que seguía al Gramsci que polemizaba con el manual de Bujarín en El materialismo histórico y la filosofía de Benedetto Crocce, y que el partido había publicado tres años antes en esa saga de publicación debida a Agosti que se ha señalado antes. En su contestación, Del Barco sostenía que 
El conocimiento científico [...] no puede brindar la certeza de la objetividad, sino apenas argumentar a favor de esta, sin darnos cuenta nunca de la realidad en sí [...]; la solución gramsciana es la genuina solución del marxismo al problema planteado. (Del Barco, 1962, citado en Burgos, 2004, p. 55)

A su vez, en el número siguiente, Olivieri respondió a Del Barco y allí sostuvo que "el autor no hace sino desarrollar algunas tesis planteadas por Gramsci" (Olivieri, 1962, citado en Burgos, 2004, p. 57), y destacó que el pensador sardo realiza un gran aporte teórico al marxismo, pero

que cuando trata de la objetividad, incurre en algunos errores [...]; no nos parece del todo correcto, por lo tanto, extraer de la obra de Gramsci[,] para una tarea de profundización, precisamente estos aspectos discutibles, tal vez los que a lo largo de toda la obra más se apartan de la filosofía marxista leninista. (Olivieri, 1962, citado en Burgos, 2004, p. 57)

Así, Olivieri no sólo descalificaba a Del Barco y su cita de autoridad, sino que también mostraba el lugar que a Gramsci se le atribuía en las filas del partido.

En el número 63, la polémica se cerró. Del Barco afirmó su postura y redobló la apuesta, pero en ese mismo número Raúl Oliva y Raúl Sierra, en nombre del comité central, sentenciaron: "estamos convencidos de que una autocrítica militante, necesaria hoy más que nunca, ha de ser un medio eficaz para aumentar la unidad ideológica en el seno de nuestro partido" (Oliva y Sierra, 1962, citado en Burgos, 2004, p. 59). Cerrar filas era nuevamente la directiva partidaria, pero también vale destacar que el llamado a la autocrítica se llevaba adelante en momentos en que el partido era cada vez más cuestionado, ante lo cual este daba por respuesta sólo una actitud defensiva.

Así, Del Barco, Aricó y un núcleo de jóvenes militantes cordobeses serían expulsados cuando Pasado y presente 
ganara la calle y desobedecieran la orden partidaria de que la revista no debía salir más, luego del escándalo producido por su primer número. El episodio cordobés producía así la primera sangría importante del partido de la década de los sesenta, porque simultáneamente Portantiero, como ya lo hemos mencionado, saldrá también del PC en Buenos Aires.

Si las disidencias no se podían plantear por adentro del partido, estas aparecían expresándose por fuera. Esa es la razón por la que Portantiero, como tantos otros, tenía reuniones clandestinas o al margen de las direcciones partidarias. En 1963, un grupo de universitarios de la FEDE, ${ }^{15}$ entre los que se encontraban Roberto Quieto y Néstor Spangaro, dos figuras importantes del sector juvenil y muy ligadas a Portantiero -el primero porque establecería vínculos duraderos con él hasta su desaparición en 1975; el segundo porque fue quien lo impulsó a afiliarse al PC en 1952-, formaron una fracción conocida como Vanguardia Revolucionaria (vR), que tuvo a Portantiero como su referente principal, con una actitud abierta de disidencia y ruptura.

Ese partido también estaba integrado por Carlos Abalo, Enrique Rodríguez, Andrés Roldán, Lila Pastoriza, Pablo Gerchunoff, Enrique Tandeter, Luis Ortolani y Liliana Delfino, entre otros. Se estima que la formación reunía aproximadamente a unos trescientos militantes de extracción universitaria y sindical (González Canosa, 2012, pp. 9-11). La agrupación rompió relaciones con el partido a mediados de 1963 por las mismas razones que esgrimían otros sectores juveniles. Su desvinculación produjo una sangría importante en la UBA, específicamente en las facultades de Derecho y Filosofía y Letras, y mermó la influencia del partido en el movimiento estudiantil.

15. La FEDE era el nombre con el que comúnmente se denominaba a los estudiantes y dirigentes universitarios afiliados al PC. Para una mirada de conjunto, no exenta, de todos modos, de toma de partido, se recomienda consultar la obra escrita por uno de sus exmilitantes (Gilbert, 2009). 
En los documentos que el grupo lanzó, se plasmaron los descontentos con la organización partidaria y se sentaron las diferencias que la fracción disidente tenía sobre los temas que desde hacía un tiempo se expresaban de forma velada. Su manifiesto de ruptura se concretó en las llamadas Bases para la discusión de una estrategia y una táctica revolucionaria, escritas por Portantiero, al igual que en el documento Los comicios del 7 de julio y las perspectivas de la izquierda.

Portantiero volverá sobre el segundo texto citado para discutir en otras oportunidades, pero dejará cerrada definitivamente su historia con el PC. Era el partido que lo había formado, que le había mostrado un mundo donde se debatían cuestiones trascendentes y donde había podido desarrollar su vocación de intelectual dreyfusard. Ese partido le había enseñado un oficio, el de periodista y crítico literario, y le había aportado un maestro, José María Aricó, que le abriría otros horizontes distintos a los proclamados por los viejos camaradas y, para lo que seguía, también un amigo, con el que no dejaría de hacer empresas futuras en una relación inseparable.

7. En busca del tiempo perdido. Hacia

la conquista de una nueva izquierda

En el número cuatro de Pasado y presente, en la sección denominada "Crítica", Portantiero publicó Un análisis "marxista" de Argentina, ${ }^{16}$ un comentario a un libro editado ese mismo año (1964) por el historiador del PC Benito Marianetti. Portantiero sostenía que las quinientas setenta y cuatro páginas del libro de Marianetti no modificaban en absoluto la interpretación del pasado y del presente de la sociedad argentina que sostenía habitualmente el grupo 
dirigente del partido. La voluminosa edición no hacía más que fungir de soporte a las tesis que se habían esgrimido en el reciente décimo segundo congreso del partido como resumen de sus casi cincuenta años de actividad.

Ya fuera del partido, esto es, sin el peso de tener que velar las críticas o hacerlas de espalda, Portantiero se despachaba contra la línea oficial respecto a su modo de interpretación y análisis de la realidad argentina. El artículo es un buen ejemplo de aquello que había de abismo entre una y otra generación, la de los dirigentes y la de Portantiero, no sólo en cuanto al modo de encarar los análisis de los procesos sociales y políticos, sino también en el papel que se le asignaba al PC.

El texto mostraba el combate que se libraba entre viejos y nuevos a propósito de cómo usar un correcto método marxista, donde el historicismo era la perspectiva elegida para encarar el análisis de la realidad. En esa dirección, Portantiero sentenciaba:

No hay en el libro de Marianetti (como no lo hay en el conjunto de la producción teórica de los comunistas argentinos) la más mínima intención de hacer partir el análisis desde un examen concreto del mundo real, se trata de casi seiscientas páginas desbordadas por la ideología. (Portantiero, 1964, p. 82)

Así, ciencia, análisis objetivo de la realidad e ideología aparecían como posturas enfrentadas. La acusación remitía a una intencionalidad política que hacía que el pasado fuera forzado a justificar el presente de la posición política partidaria. Es por esto que para Portantiero el historiador comunista presentaba una continuidad de errores basados en una deformación metodológica, pues la escuela historiográfica en la que Marianetti se apoyaba no había avanzado más allá de las tesis de Mitre e Ingenieros, sin hacer una crítica de fondo a la versión liberal de la historia argentina. 
Portantiero disparaba así, en la misma dirección que los ensayistas nacionalistas, una versión de la historia que había ganado fuerza con el primer revisionismo de los años treinta, y que acusaba tanto a liberales como a izquierdistas de esgrimir ideologías foráneas, aunque ahora, como señalara Altamirano, "se había mudado a la orilla izquierda" (2012, p. 76).

Ese aire de familia de Portantiero con los críticos del ensayo nacional estaba posibilitado por la reacción revisionista que por esos años se esgrimía frente a las lecturas del peronismo. En efecto, para todo un arco del mundo intelectual, la caída del Gobierno de Perón despertó, a poco de avanzado el Gobierno de la Revolución Libertadora, una ola crítica hacia las posiciones asumidas por los partidos de izquierda y el mundo intelectual liberal. Portantiero se sumaría a esa crítica, aunque sin abandonar posiciones de una izquierda de filiación marxista.

Para el autor, el error que mostraba el libro de Marianetti se entendía en la continuidad de una tradición progresista que los comunistas postulaban, y de la cual se colocaban como herederos. ${ }^{17}$ No obstante, a esa filiación se sumaba el hecho de que los comunistas trasplantaban el modelo teórico de Marx para el estudio de la acumulación capitalista sin reparar en que la realidad argentina portaba características diferenciadas, la más importante de ellas su condición dependiente. Por eso debía aplicarse un esquema de desarrollo que atendiera a esa particularidad:

La historiografía comunista local ubica a nuestro siglo XIX en el marco de las revoluciones burguesas clásicas, y de él saca las categorías para el análisis, cuando lo correcto es ubicarlo en el marco de la historia de la expansión colonial de los países centrales y determinar, a partir de ello, cuáles eran las tendencias reales que hubieran posibilitado un desarrollo

I7. En esa línea, que unía a Mayo con Caseros, había colocado Agosti su Echeverría, como un homenaje que debía ser rescatado y superado. 
capitalista autónomo y cuáles las que impulsaban aún mas, a pesar de ser "burguesas", la marginalidad argentina como apéndice del centro de iniciativa mundial. (Portantiero, 1964, p. 83) 18

El intelectual filiaba de ese modo a Argentina con la escena que conformaban los países del tercer mundo.

Para Portantiero, el equívoco respecto a la interpretación de la historia de Argentina iba a hacer posible que las burguesías fueran vistas como progresistas y todas las tendencias que se opusieran a ellas como reaccionarias, esto desde la visión del partido. Así, el modelo aplicado olvidaba que el crecimiento de las ciudades y el impulso burgués no eran el producto de fuerzas endógenas

sino la impostación coercitiva de formas de producción que no contribuían a robustecer en la sociedad local un mercado interior capitalista integrado, sino que, por el contrario, tendía[n] a estructurarlo en su conjunto, aun permitiendo el crecimiento residual de capas burguesas locales, como "campaña" de la "ciudad" que era la metrópoli europea. (Portantiero, 1964, p. 83)

Por ello, Portantiero ya no creía, profundizando el juicio que había sostenido soterradamente en el número uno de Pasado y presente, que fuera posible aliarse con sectores progresistas para llevar a cabo la revolución democrático-burguesa como paso previo a la revolución socialista. Quedaban así, de un lado, los liberales y los viejos partidos de la izquierda con sus esquemas clásicos sobre la realidad argentina -entre los que también se contaba el desarrollismo que había inspirado a las ciencias sociales nacientes en los años cincuenta-, y del otro los sectores alistados en una nueva izquierda que postulaba que la única salida a la situación de dependencia era preparar las bases para en un solo movimiento hacer posible revolución nacional y

18. Itálicas en el original. 
revolución social. La segunda senda la marcaban la Revolución cubana, el proceso de descolonización y Cooke desde el peronismo.

Ahora bien, la batalla respecto al historicismo se debía dar primero en el plano de la teoría, y enfocado este en el análisis correcto del estado de situación política. Por eso, Portantiero anotaba:

La oposición mecánica y libresca de las categorías "burguesía" y "feudalismo"[,] tal como se leyeron en las vulgarizaciones de Marx, preside la historiografía comunista local, aislándola de la interpretación científica de los conflictos en la sociedad nacional y fijando las líneas de una estructura de pensamiento cosmopolita, no nacional popular, que se expresa también en el enfoque de la historia presente. (Portantiero, 1964, p. 83)

Dicho esto, si se quería llevar a cabo un análisis científico de la sociedad, Gramsci aparecía como el lente para descifrar el devenir histórico, y allí también es donde su pensamiento volvía a filiarse con la historiografía nacional.

Portantiero sostenía que Marianetti no discriminaba, tal como mandaba Lenin, entre si las fuerzas del desarrollo eran autónomas o, por el contario, si al desarrollo moderno lo impulsaba el capital extranjero. Argentina era, para nuestro autor, en los términos que lo había planteado el revolucionario ruso, una colonia. Así, el Lenin teórico del imperialismo se amalgamaba con la lectura del Gramsci teórico de la revolución en clave nacional popular. Esas referencias mostraban que era el marxismo el lugar en donde se debatía.

En aquella larga reseña, Portantiero combinaba calificativos denigrantes con un análisis exhaustivo del libro. Por eso dirá que la liturgia le ganará a la lógica, y que todo el asunto del libro no es más que la aplicación del catequismo que promueve el partido. Lo tildará de candoroso cuando su autor se refiera a Mitre y a su política desde la presidencia, 
todo ello amparado en la invención de "una inexistente "tradición progresista"' (Portantiero, 1964, p. 85). ${ }^{19}$

Estos calificativos mostraban a las claras que la burguesía no podía cumplir ninguna tarea, y que sólo había dos frentes posibles: de un lado, el del imperialismo, y del otro el del proletariado. De ahí que ni Marianetti ni sus camaradas podrían, a ojos de Portantiero, estudiar científicamente la lucha de clases, porque no englobaban el conjunto de la investigación en el marco del desarrollo capitalista en los países explotados, de modo que todo lo que harían "será mera ideologización" (Portantiero, 1964, p. 85).

Para nuestro autor, de todo ello vendrían los errores cometidos en el presente, pues de la deformación histórica del pasado se derivaban los desaciertos políticos en la realidad nacional. Por eso, dirá que la unión democrática es una alternativa política a lo que del otro lado no se ve sino como, en las palabras del máximo dirigente Codovilla, naziperonismo, cuando

Todo el conflicto real que para la sociedad argentina suponía el crecimiento industrial con la aparición de nuevas clases; la necesidad inevitable que esas clases tenían de participar en la conducción del Estado [...]; toda la riqueza del proceso ( $i$ entre otras cosas encerrando nada menos que la aparición de un nuevo proletariado!) queda atrapada [...] en la disyuntiva [entre] fascismo o democracia. (Portantiero, 1964, p. 85)

Portantiero había compartido con otros artículos de Pasado y presente un diagnóstico sobre la obsoleta y errónea manera de mirar los procesos políticos, y atacaba la forma en que se clasificaba al peronismo, cuyo significado Portantiero deslindaba de su líder.

Así, el hecho peronista era una vez más la cuestión que dividía el campo político e intelectual y penetraba como una

19. Las comillas son del original.

\section{6}


grieta las filas del marxismo. El tópico de la incomprensión del hecho peronista estaba en el centro de la descalificación del, entonces ya, viejo partido de Portantiero. La polémica no era nueva, en efecto: como se recordará, luego de la caída del Gobierno de Perón, el frente antiperonista comenzó a desdibujarse, y poco a poco las descalificaciones tanto a los partidos tradicionales de la izquierda (Socialista y PC) como a las posiciones del arco liberal del campo intelectual comenzaron a ser el blanco de las nuevas narrativas de las nuevas generaciones y de algunos miembros de esas fracciones ahora acusadas. ${ }^{20}$

Para cuando Portantiero arremetiera contra Marianetti, ese combate ya estaría consumado, pero este disputaría su posición desde adentro del marxismo, de ahí que Portantiero pudiera sostener: "Como para el pasado histórico, ni el más remoto análisis clasista participa del método con que Marianetti y sus camaradas afrontan la realidad argentina" (Portantiero, 1964, p. 85), porque el proletariado quedaba encerrado en un esquema que dividía, por un lado, a las fuerzas progresistas y democráticas, y por el otro a las fuerzas del fascismo y el totalitarismo.

Toda esta invectiva estará formulada en términos de una oposición tajante: método científico versus estructura analítica anclada en la ideología -en la que se transpolaba mecánicamente una teoría foránea sin asiento en la realidad nacional, como ya se dijo-. Para Portantiero, toda la estrategia política del PC anterior y posterior al periodo peronista se cifra en ese tenor, de ahí la responsabilidad del fracaso de la izquierda, responsabilidad que para el PC será aún mayor por tratarse de la estructura orgánica más compacta, con cuadros dirigentes que jugaban su madurez política en el escenario argentino.

20. Para un análisis de esa incomprensión y de la cuestión peronista como el nervio del campo cultural, véanse:Altamirano (200I) y Sigal (2002). 
La teoría de la revolución democrático-burguesa, y con ella el papel de los sectores progresistas, como también la caracterización del papel del imperialismo que el libro de Marianetti postulaba eran para Portantiero otros diagnósticos errados de una saga que comenzaba con la postulación, foránea y simplista, decía nuestro autor, de la dicotomía feudalismo-capitalismo, en la que el imperialismo era postulado como un fenómeno externo, mientras para Portantiero, en cambio, el imperialismo formaba parte de la estructura del desarrollo argentino en la forma del desarrollo combinado, de modo que para extirparlo no podía llevarse adelante otra cosa que la revolución social.

Aquí se encontraba otra diferencia fundamental, ya que, en su visión, el imperialismo no era un factor externo; por eso sostenía que el transformismo que el pc llevaba adelante con su apoyo al radicalismo, primero de Frondizi y luego de Illia, no hacía sino realizar "los sueños de las capas medias" (Portantiero, 1964, p. 86). Con esa arremetida concluía, no sin cierto sarcasmo, que el libro de Marianetti tenía un valor, ya que era el "testimonio de la esclerosis de pensamiento; de una incapacidad inaudita de plantear y resolver originalmente los problemas de la realidad argentina en su pasado y su presente" (Portantiero, 1964, p. 86). Así caracterizado, el PC no sólo no representaba a la clase para la cual había nacido, sino que además representaba un modo errático del pensamiento y la política argentina.

Ese análisis se inspiraba fuertemente en las Tesis de abril, donde Lenin (2014) llamaba, poco antes del triunfo definitivo de los bolcheviques, a quebrar las alianzas con los sectores moderados y a fundar las condiciones para colocar el poder del lado del proletariado revolucionario y las masas campesinas, lo que dejaba toda política defensiva al tomar en cuenta la ampliación del proletariado con capas que habían despertado recientemente a la vida política. 
La tarea del partido en la visión leninista era la de adaptarse a la nueva situación sin hacer concesiones a los sectores no revolucionarios, de los cuales sacarían provecho sólo las fracciones capitalistas. En su folleto, el revolucionario ruso llamaba a quitar el apoyo al Gobierno provisional para construir una estrategia revolucionaria sin volver a dar sostén a los sectores de la pequeña burguesía, aun cuando estos se llamaran socialistas.

En esa clave leninista era leída por Portantiero la estrategia del viejo PC en Argentina, con su política de alianzas y apoyos tácticos que buscaban la forma de llevar adelante la revolución democrática burguesa. Portantiero, por el contrario, que ya había pasado definitivamente a las filas de la nueva izquierda, no podía pensar en alianzas con sectores de la burguesía ni sus representantes. No podía ya desplegarse una política moderada y etapista. Un influjo cubano y tercermundista se amalgamaba con la inspiración nacional popular de Gramsci.

\section{El método de la guerrilla como contestación de la nueva izquierda}

Si el PC postulaba la vía pacífica para cumplir con las etapas necesarias para salir del atraso de cara al socialismo, Portantiero ya veía como posibilidad la vía insurreccional, amparado como estaba en la certeza de que el reformismo se había acabado y que se estaba frente, como sostuviera en el primer artículo de Pasado y presente, a una situación revolucionaria. El método de la guerrilla para saldar la crisis y llevar adelante el socialismo estaba apuntado por las condiciones de una semidemocracia (Cavarozzi, 2012) y el prestigio que tenía la Revolución cubana. Como ya se ha señalado, la gesta cubana sería el centro de gravedad sobre el cual giraría toda la discusión de la izquierda de los 
años sesenta. En ese sentido, probar la vía armada como una posibilidad no se haría esperar.

En efecto, la experiencia llevada adelante por el Ejército Guerrillero del Pueblo (EGP), al que Portantiero prestará apoyo a partir de 1963, será la experiencia política con la cual se contestará su salida del partido. Así, el grupo cordobés de Pasado y presente y Portantiero -como parte de VR- se vincularon al EGP, comandado por Jorge R. Masetti, que se estableció en la provincia de Salta como parte de los planes de "El Che" Guevara para hacer la revolución en Argentina.

Masetti era un periodista argentino que había cubierto para la estación de radio El Mundo, de Buenos Aires, los combates en Sierra Maestra de la guerrilla del movimiento 26 de julio, liderada por Castro y Guevara cuando estos luchaban por derrocar a la dictadura de Fulgencio Batista en Cuba, en 1959. Los reportajes sobre los líderes guerrilleros fueron retransmitidos a la población cubana por la radio rebelde, pero no pudieron ser captados por la emisora de Buenos Aires. Masetti se enteró de ello al llegar a La Habana, y a raíz de lo ocurrido el periodista, tomando serios riegos, volvió al lugar para registrarlo de nuevo en su grabadora y poder llevarlo a Buenos Aires, en un hecho que le valdría un halago de parte de Rodolfo Walsh, quien se refirió a la labor periodística de Masetti como "La hazaña individual más grande del periodismo argentino" (Masetti, 1961, p. 2).

De este modo, además de ganar estatura de héroe, Masetti trabó por esos años una estrecha relación de amistad con Guevara y se convirtió en uno de los hombres de mayor confianza del líder guerrillero. Así fue como fundó, a instancias de "El Che", la agencia de noticias Prensa Latina, y abandonó su puesto de periodista en Buenos Aires para unirse a la revolución triunfante. En esa empresa, se dio a la tarea de conseguir apoyo material en los países que estaban en el radio de acción de la Unión Soviética, y salió en busca de jóvenes periodistas en Buenos Aires y otros países 
de la región para realizar la tarea. Ofició de director de un acreditado elenco de redactores, entre los que se encontraban, como corresponsales extranjeros, Jean Paul Sartre por Francia, Eduardo Galeano por Uruguay, Rodolfo Walsh por Argentina y Waldo Frank por Estados Unidos. Esto le valió un enorme prestigio entre los intelectuales radicalizados del continente que simpatizaban con la Revolución cubana.

Luego, en 1961, Masetti dejó su puesto de periodista para convertirse en guerrillero, y así participó de la resistencia cubana ante la invasión estadounidense de Bahía de Cochinos, y un tiempo después prestó servicios militares en Argelia. A su regreso a Cuba, y luego de someterse a un entrenamiento para convertirse en un soldado profesional que duraría varios meses, inició la misión encomendada por "El Che" Guevara de instalar un foco guerrillero en Salta con el nombre de Comandante Segundo.

En 1963, instalado en el pueblo de Orán y previo paso por Bolivia, el ejército de Masetti, que contaba en ese momento con pocos hombres, envío a Ciro Bustos, un artista plástico oriundo de Mendoza, primero a Córdoba y luego a Buenos Aires para funcionar como enlace de la guerrilla en la ciudad. Las tareas de Bustos consistían básicamente en el reclutamiento de voluntarios para que se sumaran al foco guerrillero en el norte y construyeran un partido de propaganda que tuviera inserción de masas (Bustos, 2004). Sus contactos en Córdoba eran principalmente Oscar del Barco y parte del grupo que editaba Pasado y presente. En Buenos Aires, Bustos se contactó con Portantiero a instancias del grupo cordobés, y este a su vez lo condujo a una reunión con un grupo de universitarios dispuestos a sumarse al foco guerrillero (Bustos, 2004, p. 152). Así, el brazo urbano del movimiento guerrillero comenzaba a tomar forma.

Llegado este punto, la pregunta que podría formularse en aras de comprender la situación sería ¿por qué todo el grupo cordobés y Portantiero no habían dudado en sumarse 
al proyecto, dado que si bien este último no creía en la vía pacífica en las condiciones de Argentina, también sostenía en sus escritos que las condiciones subjetivas para la revolución en el país todavía no estaban dadas?

Para acceder a una respuesta, no debe olvidarse que Bustos hablaba en nombre de "El Che" y de Masetti, y que uno y otro portaban un prestigio que no tenía ningún otro dirigente de izquierda en la región: los dos argentinos se habían convertido en el camino a seguir si se quería ser revolucionario. La proscripción del peronismo hacía otro tanto: para muchos de los jóvenes que en los tempranos años sesenta se acercaban a la política, las condiciones de Argentina hacían que la vía armada fuera poco a poco cada vez más una salida.

\section{El viaje a Cuba. Sueño de todo revolucionario}

Portantiero conoció a Guevara en Cuba en 1961 como corresponsal de la revista Che, publicación que había iniciado un grupo de disidentes del Partido Socialista argentino. En 1960, el PC, tratando de ganar terreno en el espacio de la izquierda -que venía perdiendo desde que el peronismo le arrebató la representación de la clase obrera-, inició una alianza con los viejos socialistas y envío a Portantiero a la isla como su corresponsal de la mencionada revista.

El encuentro en que Portantiero conoció a Guevara y a Raúl Castro quedó registrado en las dos notas que, como crónicas de viaje, escribió ese mismo año. Lo que había sido un encuentro casual con Raúl Castro a la salida de un cine fue convertido por el oficio de periodista de Portantiero en un fresco que retrataba los logros de la revolución. Escrito en primera persona, el texto describe la sorpresa que le causó la isla en su visita cuando creía, según sus palabras, conocer todo sobre ella. 
El eje alrededor del que gira el relato es su estadía en la isla a propósito de la invasión contrarrevolucionaria a Playa Girón. En la respuesta del pueblo y sus dirigentes, Portantiero describe el heroísmo y las conquistas del nuevo Gobierno. En la historia de Patricia Silva, de 19 años, miliciana y maestra voluntaria, resumirá la lucha por la defensa de los logros de esos años. Así, toda esa crónica muestra "la primera derrota militar del imperialismo yanqui en tierras de América [...]. Y, además, el triunfo de la conciencia socialista en el grueso de la población cubana" (Portantiero, 1961a, p. 143).

Para Portantiero, la invasión a Playa Girón había marcado un antes y un después, y el después era jalonado por la resistencia porque a partir de esa fecha "se robusteció la cohesión indestructible de un pueblo. Su cohesión socialista" (Portantiero, 1961a, p. 144). En ese doble movimiento, se cifraba todo el valor de la revolución, porque esa Cuba socialista "inserta a nuestro continente en pleno corazón de la historia contemporánea" (Portantiero, 1961a, p. 139). La gesta tenía un valor notable; mostraba que ya no hacía falta mirar al otro lado del Atlántico para ver la realización del socialismo: esto sucedía en América, y ahora certificaba que era posible la revolución en el continente, y que esa lucha, al mismo tiempo, se enlazaba con las que llevaban adelante los países del tercer mundo.

Era en la lucha, además, donde la conciencia socialista se mostraba más clara, como lo evidenciaban la cohesión del pueblo y la miliciana, que frente al invasor gritaba "¡Patria o muerte! ¡Venceremos!” (Portantiero, 1961a, p. 143). Esa conciencia socialista era precisamente lo que faltaba en Argentina, donde los viejos dirigentes del PC no salían de sus clásicos esquemas y la alianza con los obreros estaba escindida. Mostraba Cuba, así, un espejo donde mirarse. 
Incluso, había un elemento más a considerar. La dirigencia cubana enseñaba la actitud de un verdadero revolucionario:

Ni bien se tuvo noticias del desembarco, Fidel marchó para la zona. Era el comandante en jefe, pero no el comandante en jefe que corre banderillas sobre un mapa en un despacho céntrico con aire acondicionado: era el comandante en jefe en el campo de batalla. (Portantiero, I96 Ia, p. I4I)

El compromiso de estar en el campo de batalla dotaba al comandante Castro de un prestigio que no tenía ningún otro dirigente de izquierda. Muy diferentemente sucedía en el partido argentino, al que todavía pertenecía para entonces Portantiero, que expresaba con mucha cautela su oda a los cubanos. Se abría así, para el intelectual, un abismo entre una figura y otra. Además, no sólo las palabras del cronista contaban la gesta, sino que la de los mercenarios hablaba por sí sola de la transformación:

Horas antes de llegar a Playa Girón, más de quince días después de la frustrada invasión, cuatro mercenarios se entregaron [...]. Hablé con ellos [...]. La conversación, grabada en una cinta, ilustra bastante sobre la aventura invasora [...].

- iPiensa ahora igual que antes? [pregunta Portantiero]

-No, esto es muy diferente.

- ¿Por qué?

-Porque es una Cuba distinta a lo que nos habían dicho. Es muy distinto a lo que yo conocía. Esto era monte completo. (Portantiero, I 96 I b, p. I 46)

El testimonio de los invasores permitía demostrar que el cronista contaba lo que veía, y que ellos también reconocían los logros de la revolución; que su palabra no sólo no podía ser desmentida, sino que ahora era corroborada por los invasores. 
El mismo despliegue de su oficio como periodista se da cuando Portantiero describe su encuentro con "El Che", y también nuevamente los revolucionarios aparecerán de un modo amigable para el lector y construirán rápida empatía con el relato. Sobre el hermano de Fidel, Portantiero dirá que, en sentido inverso a lo que se escribe sobre él, en que se le califica como un ser despiadado, frío, oculto y fanático iracundo,

Raúl Castro es todo lo contrario. Dentro del común aire amuchachado que tiene la Revolución cubana, Raúl es el escalón más joven [...] una especie de máquina para hacer cosas [...]. Pero sobre todo es un muchacho menor de treinta años que habla, bromea, sonríe, como un muchacho menor de treinta años. (Portantiero, 196I, p. 147)

Sobre esta cuestión, hay algo que debe destacarse: quien escribe es también un muchacho menor de treinta años. Mucho se ha dicho sobre la instancia generacional que rodeó a la nueva izquierda latinoamericana, pero poco se ha destacado el aspecto emocional que esa corriente contuvo. En efecto, la empatía con la Revolución cubana tuvo muchos aspectos destacables, pero más allá de la pertenencia a la misma familia ideológica muchos encontraron, como en este caso, una cercanía de otro orden, porque lo que muestran las palabras de Portantiero es que hay una estructura de sentimientos que va más allá de la ideología y que convierte a esa experiencia en algo vital. Después de todo, Raúl era un muchacho como él, pero que estaba haciendo aquello que él y su generación sentían que debían hacer.

Sobre el encuentro casual con Raúl Castro, el argentino relató que la comitiva de su país en Cuba fue una tarde a un cine y "Allí como un espectador más estaba Raúl [...]" (Portantiero, 1961b, p. 148). La imagen estaba lejos de la que este joven cronista tenía de Stalin y los dirigentes soviéticos en general, y de los viejos dirigentes del PC. El relato 
marcaba una disolución de las fronteras de las jerarquías y colocaba a la dirigencia cubana al mismo nivel que el pueblo y que él mismo. No podría no estarse de acuerdo en que esta dirigencia revolucionaria fundaba su legitimidad también en su postura pública, y en que la encumbraba no sólo su accionar afable, sino también las transformaciones operadas en la geografía para disolver los símbolos de la desigualdad social.

Eso mismo mostraba el relato de Portantiero de su encuentro con "El Che", un día después del de Raúl Castro. Relata el intelectual que esto sucedió en El Ciudamar Yacht Club de Santiago de Cuba, "una maravilla al borde del mar, que acaba de ser nacionalizado y transformado en un Círculo Social Obrero, como todos los clubes de las clases altas" (Portantiero, 1961b, p. 148). La revolución proletaria estaba ahí para que todos pudieran apreciarla: los símbolos de la oligarquía disueltos y convertidos en estructuras que mostraban las transformaciones de la revolución. Si la geografía se transformaba, esto quería decir que las transformaciones eran estructurales. Ese fresco que Portantiero pintaba sobre Cuba le enviaba al lector la imagen de la revolución socialista que todos buscaban.

En su relato, el argentino dirá sobre Guevara: "Lo vemos y pensamos: temperamentalmente, de alguna manera, Ernesto Guevara sigue siendo un porteño, aunque ese ligero acento cubano ronde sus expresiones" (Portantiero, 1961b, p. 148). Aquí de nuevo la crónica muestra eso que se ha venido sosteniendo: la empatía y lo emocional juegan un papel central para entender la identificación con los revolucionarios.

La entrevista es también una muestra de la importancia de las ideas de Guevara en el acervo del joven Portantiero. Así, frente a la pregunta sobre la toma del poder y la construcción social de la revolución, Guevara señalaba: “[...] el 26 es la expresión de la lucha contra el quietismo de los partidos 
tradicionales [...]. En la Cuba batistiana no había margen para la lucha legalista [...]" (Portantiero, 1961b, p. 149). Como se dijo, un diagnóstico similar esbozará Portantiero poco tiempo después en su primera intervención en Pasado $y$ presente, cuando el joven militante de izquierda consuma así el parricidio y su ajuste de cuentas con su viejo partido al que, al igual que sus camaradas de la misma generación, no le atribuirá un papel central en el camino al socialismo.

\section{A modo de conclusión}

Como hemos visto en este recorrido por el itinerario de Juan Carlos Portantiero en sus años de formación, los intelectuales van forjando sus ideas al calor de los espacios institucionales que les dan lugar, y también como consecuencia de las ideas de su tiempo y de la camaradería que estos encuentran en el camino hacia la construcción de una posición intelectual.

En ese sentido, el influjo generacional que tuvo la Revolución cubana aparece como decisivo para una formación de militantes de izquierda que en los años sesenta, en Argentina en particular y en el continente en general, desafiaron las ideas y las directrices de los partidos tradicionales de la izquierda.

También es fundamental entender que la modernización cultural en Argentina coincidió con una renovación de las ciencias sociales que hizo posible que las nuevas generaciones intelectuales vieran como obsoletas las herramientas de análisis de los partidos tradicionales para el examen de la realidad, elemento decisivo a la hora de caracterizar la formación de los intelectuales y que se propone como material para un análisis posterior. 
Altamirano, C. (200 I). Bajo el signo de las masas (1943-1973). Buenos Aires:Ariel Historia, Biblioteca del Pensamiento Argentino VI.

Altamirano, C. (20I2). Peronismo y cultura de izquierda. Buenos Aires: Siglo XXI.

Aricó,J.( (1963). Pasado y presente. Pasado y presente, I (I), 5-7. Aricó, J. M. ( 1988). La cola del diablo. Itinerario de Gramsci en América Latina. Buenos Aires: Punto Sur.

Burgos, R. (2004). Los gramscianos argentinos. Cultura y politica en la experiencia de pasado y presente. Buenos Aires: Siglo XXI.

Cavarozzi, M. (2012). Autoritarismo y democracia (1955-1996). La transición del Estado al mercado en la Argentina. Buenos Aires:Ariel.

Coser, L. (1968). Hombres de ideas. El punto de vista de un sociólogo. Buenos Aires: Fondo de Cultura Económica.

Crespo, H. (1999). Poética, política, ruptura. En N. Jitrik (Dir.), Historia crítica de la literatura argentina. La irrupción de la crítica (pp. 423-462). Buenos Aires: Emecé.

Gilbert, I. (2009). La FEDE. Alistándose para la revolución. Buenos Aires: Sudamericana.

Gilman, C. (2003). Entre la pluma y el fusil. Debates y dilemas del escritor revolucionario en América Latina. Buenos Aires: Siglo XXI.

González Canosa, M. (20I2). Hacia la conformación de los dos grupos fundadores de las far (Fuerzas Armadas Revolucionarias). Itinerarios políticos-ideológicos recorridos por sus militantes en la década del sesenta [ponencia presentada en el marco del congreso de la Latin American Sociological Association]. LASA: Río de Janeiro.

James, D. (2010). Resistencia e integración. El peronismo y la clase trabajadora argentina. 1946-1976. Buenos Aires: Sudamericana. 
Lenin,V.(20I4).Tesis de abril. En V. Lenin (Aut.), Obras selectas.

Bibliografía Tomo I (pp. 43-47). Buenos Aires: Ediciones IPS.

Mannheim, K. (1963). Ensayos sobre sociología de la cultura. Buenos Aires: Fondo de Cultura Económica.

Masetti, J. R. (I96I). Los que luchan y los que lloran. Buenos Aires: s/e.

Massholder,A. (20I3). El Partido Comunista y sus intelectuales. Pensamiento y acción de Héctor P. Agosti. Buenos Aires: Ediciones Luxemburg.

Mocca, E. (20I2). Juan Carlos Portantiero. Un itinerario político e intelectual. Buenos Aires: Ediciones Biblioteca Nacional.

Petra, A. (20I7). Intelectuales y cultura comunista. Itinerarios, problemas y debates en la Argentina de posguerra. Buenos Aires: Fondo de Cultura Económica.

Portantiero, J. C. (I 96/ I). ¿Qué es Cuba socialista? Che, (I), I32-I 44.

Portantiero, J. C. (I $96 \mathrm{Ib})$. Cuba: detenerse es retroceder. Con "El Che" y Raúl, en Santiago de Cuba. Che, (I), I5I-I52.

Portantiero, J. C. (1963). Política y clases sociales en la Argentina actual. Pasado y presente, I, I8-24.

Portantiero, J. C. (1964). Un análisis "marxista" de la Argentina. Pasado y presente, 2, 34-42.

Portantiero, J. C. (2005). Entrevista personal [J. M. Casco, entrevistador]. Buenos Aires, Argentina.

Portantiero, J. C. (2006). Entrevista personal [J. M. Casco, entrevistador]. Buenos Aires, Argentina.

Ribadero, M. (20I7). Tiempo de profetas: ideas, debates y labor cultural de la izquierda nacional de Jorge Abelardo Ramos (1945-1962). Buenos Aires. Universidad Nacional de Quilmes.

Sarlo, B. (200I). La batalla de las ideas (1943-1973). Buenos Aires: Ariel Historia, Biblioteca del Pensamiento Argentino VII. 
José María Casco

Bibliografía $\quad$ Sigal, S. (2002). Intelectuales y poder en la Argentina. La década del sesenta. Buenos Aires: Siglo XXI.

Terán, O. (1993). Nuestros años sesentas. La formación de la nueva izquierda intelectual argentina, 1956-1966. Buenos Aires: Ediciones El Cielo por Asalto.

Tortti, M. C. (2009). El "viejo" partido socialista y los orígenes de la "nueva" izquierda. Buenos Aires: Prometeo.

Tortti, M. C. (Comp.) (20I3). Che. Una revista de la nueva izquierda. Buenos Aires: Ediciones del CEDINCI.

Tortti, M. C., y Chama, M. (2006). Los "nudos" políticos e intelectuales de una trayectoria. Entrevista a Juan Carlos Portantiero. Cuestiones de sociología. Revista de estudios sociales, (3), 232-254. Recuperado de https:// www.cuestionessociologia.fahce.unlp.edu.ar/article/ view/CSn03al I/5753 